\title{
Research on the Application of Modern Multimedia Technology in Music Teaching
}

\author{
Shuang Zhao ${ }^{1, \text { a }}$ \\ ${ }^{1}$ College of Music, Beihua University, Jilin 132013, China. \\ ashuang_zhao002@126.com
}

Keywords: music education, multimedia system, application.

\begin{abstract}
With the computer technology development, the multimedia system in music teaching has been applied to the domain of music education in domestic. in this paper, the necessity, idea and significance of modern multimedia technology in music teaching is investigated, and the specific usage of multimedia system is discussed and conceived. The thesis attempts to provide testimony for the application of multimedia technology to music education.
\end{abstract}

\section{Introduction}

Since the 20th century, since the 1990s, the booming multimedia technology, its application has spread to every corner of social life trick, is to give people the mode of production, work and even a huge lifestyle change; especially because of having a multimedia graphics, and text, sound and Mao even activity characteristic of the image, it is possible to create more than the traditional music education the ideal teaching environment, are bound to have a profound impact on music education.

The meaning and scope of multimedia technology is extremely broad, difficult to give a precise definition used here Lippincott definition given in 1990: multimedia computer technology is a computer with an integrated handle a variety of media information - text, graphics, images and sound, so that a variety of information to establish a logical connection, integrated into one interactive system. Processed applications of multimedia technology, the computer may include text, graphics, images, video, animation, and sound information, and can handle a variety of information and use it together. Multimedia technology with integrated, real-time, interactive and high-quality features.

With the multimedia technology has become more sophisticated and popularity of multimedia technology in education is more common. Multimedia Computer Assisted Instruction is a new trend in the current educational development at home and abroad, and has become an effective way of teaching the doors. In the United States, computer technology is applied to the music classroom, laboratories, concert halls, involving almost all aspects of music teaching and research. For example: Students in a computer display of the acoustic record, analyze their singing pitch, tone and legato vibrato, these sound waves generated in the recording of the actual performance of students or recent voice lessons on videotape; watching the famous play on the big screen multimedia home performances; according to the rhythm of sound clips and sound system to provide computer improvisation exercises; use of automatic accompaniment program and interactive accompaniment and solo practice procedures; use notation software to record and score points spectrum; using computer-aided teaching program based music teaching and practice listening skills. University of Music (including Music Education) graduates must be able to work within the scope of his skilled use of computer.

In comparison, China's music education in the application of multimedia technology is even lagging behind, although the Central Conservatory of Music and the Capital Normal University and other colleges and universities have begun to use some of the modern teaching methods, and set up the relevant technical courses, but most schools in teaching music still continues the traditional teaching methods and teaching means. Some have the ability to carry out multi-media teaching in schools, although configured with the modern teaching facilities, but due to lack of teachers and so handy multimedia courses nominal. Multimedia technology in teaching music represents a new teaching ideas and teaching mode, is considered the following text appears in the history of human education, the school was founded, after the fourth revolution of movable type, it is the requirements 
of modern education. Modern Education said: modern education, in addition to ideological, educational goals, the modernization of the educational content of education, but also to reflect the modern educational methods, teaching methods. To this end, multimedia-assisted teaching has aroused widespread concern in the education sector, multimedia technology widely used in music education is an inevitable trend.

\section{Constructivism Theory and Multimedia Technology}

Constructivism also translated as structuralism, from the earliest school of Geneva, Switzerland, the famous psychologist Jean Piaget theory of cognitive development of children. He believes that children are in the process of interaction with the surrounding environment, and gradually construct knowledge about the outside world, so that their cognitive structure has been developed. On the basis of Piaget's theory, later again in the nature and conditions for the development of cognitive structures, individual initiative and critical role in the construction of the cognitive process cognitive process of how to play individual initiative and other aspects are further research and exploration. In recent years, with the growing popularity of multimedia technology, constructivist learning theory gradually attracted widespread attention, according to the constructivist theory of teaching reform pilot study schools is also increasing, although the reasons for the development and construction of the advanced nature of the minute Theory open, but we should also see the rapid development of multimedia technology in recent years, making ideal conditions constructivist learning environment matured, multimedia technology and network features and functions most conducive to the four elements of constructivism learning environment contains the "Circumstances "," collaboration "," session "and" meaning construction "fully reflects, this is an important impetus for its development and with the combination of school teaching.

Constructivist learning theory emphasizes the creation of real-life situation, the creation of scenarios as "meaning construction" necessary premise, and as the most important elements of instructional design. The multimedia technology is precisely the most effective tool for the creation of real situations, if combined with simulation technology, the better to have a feel of realism. Music Teaching students need to provide a lot of audio-visual stimulation, can play its multimedia technology is powerful; "authenticity music Tasks" is an important issue in modern music education theory, but also the new "music curriculum standards" to the majority of music teachers make teaching requirements, a variety of multimedia software, audio and video databases, electronic mixer, analog music, virtual concerts, etc undoubtedly achieve this new task of paving the way.

As the purpose of learning, meaning the construction rely on students to consciously take the initiative to complete the role of teachers and the external environment is to help and promote the students construct meaning. Multimedia technology because it can provide user-friendly, visually interactive learning environment (in favor of the students take the initiative to explore, take the initiative to find), Telemetry can provide sound and Mao comprehensive multi-sensory stimulation, but also by hypertext organization and management of the kinds of music and music education information knowledge (in favor of the development of associative thinking and establish links between the old and the new concept), and thus the formation and development of students' cognitive structure that the students have learned about the significance of the current knowledge of the construction is very strong, but also in other media or other teaching environment can not match.

Modern education in order to promote the subjectivity of students, students of the spirit of innovation as the core. The application of information technology in teaching, help to achieve these goals. Therefore, the information technology has become the technology platform of modern education, to provide technical support for the implementation of modern education. Constructivism modern education based on the theory, information technology is used in teaching Constructivism prerequisite. Since constructivist learning environment required to obtain the latest information and technological achievements of contemporary strong support, which makes the constructivist theory quickly out of the ivory tower theorists, teachers and teaching practice increasingly widespread 
combined, making at all levels, deepening the reform of all types of schools teaching the guiding ideology and reform of traditional thought and the concept of education sharp weapon.

\section{Application of modern multimedia technology advantages}

Compared with the traditional music education model, modern multimedia technology in music teaching traditional teaching incomparable advantages, to build a new constructivist teaching model of multimedia technology environment will also become a new model for future modern music teaching, as a new Music means of education, multimedia technology in music teaching, for teachers and students to have a whole new meaning.

Classroom teaching is teaching all a key part of classroom teaching efficiency level will directly affect the quality of teaching and teaching effectiveness, how to get the best teaching results in just a few tens of minutes is why many teachers constantly thinking and exploration The problem. With respect to the teaching of other subjects, the music has its own teaching and the unique particularity of music is to learn more dependent on personal feelings of understanding, which requires more varied forms of music teaching, the traditional form of music teaching single, teaching tools are limited to a piano, a tape recorder only, lack of intuitive teaching process, it is difficult to create a good teaching atmosphere. For example, university teaching harmony, lack of the necessary audio-visual links, school teachers rely on a blackboard and chalk for writing and analysis of harmony can only do four boring to explain, even if only a piano as simple aids demonstration, but it can not exhibit the piano harmonies rich effect. For students only have some basic essentials and rules, but not really appreciate the charm of harmony. The use of multimedia technology in teaching, teaching software with professional harmony, can show the individual parts were in the classroom, but also can hear the actual sound of each part or all of the voices sound so intuitive the teaching of harmony, not only for students with theoretical and practical harmony sound understanding and mastery of the double, but it will also greatly improve the efficiency of teaching harmony courses.

In teaching music appreciation course, the traditional way of teaching aids used by only a tape recorder, and audio tapes are stored analog recording, the effect will also increase the time the tape is reduced, resulting in musical works many musical elements in the recording is not easy to identify them; at the same time, the recorder itself wear and aging also affects the quality of playback, and often make us feel the same tape recorder on different playback speeds will differ because the recorder shaft belt tension caused by different causes at different speeds, this will also affect our appreciation of the effect, moreover, often to listen to repeatedly listen to a section or in a separate appreciation class, teachers spend time in rewind, fast forward, on the back and other operations, there is a designated point to find slow, inaccurate and other shortcomings select the playback starting point, but also a waste of valuable class time. And the use of multimedia computers and audio features advantages in these areas is very clear, any music can be free to select any section of a piece of music of a film, audio file can be any arbitrary one second a minute from the selected, each time the playback speed there will be no difference, and the computer can quickly set the music according to the teacher's request, the image of a paragraph repeatedly. For music works in some instruments or voices need to emphasize the part in the file can always set up one or several parts solo, allowing students to hear, and then play the whole song comparing these methods to further improve the students for understand and master the song, while saving time teaching, improve teaching efficiency.

A complete system of teaching can not be separated to assess the overall system. Teaching evaluation and feedback is to test the quality of teaching and learning system continuously improve and perfect the important part. Music is the music teaching evaluation process of teaching an indispensable part, it has other processes irreplaceable function in the teaching process. Traditional music exam often main emphasis on evaluation of general knowledge and skills of music while ignoring the quality assessment of student musical aesthetic thinking and emotional aspects. 


\section{Construction of multimedia technology in teaching music}

Advantages of modern multimedia technology in music teaching in the majority of teachers have not been universally accepted, some teachers still continues to date the traditional concepts of education and teaching methods, and that multimedia technology in music teaching is superfluous, worthless. Therefore, to promote and popularize the work of multimedia technology is very urgent. Promotion and popularization There are many ways, for example, can organize teachers to have undertaken multimedia technology teaching and research units and school field trips and learning; it can ask in multimedia musical instruction of experts to the school were popular lectures, in order to allow teachers to really get in touch and understand the application of multimedia technology to our music teaching convenience, thereby gradually changing traditional concepts of education teachers, so that they accept and agree with multimedia technology is fully applied to music teaching from the bottom of my heart. This is the first step to carry out multi-media teaching.

Multimedia technology in teaching music combines the expertise of a variety of computer knowledge, software knowledge, musical knowledge, the scope of knowledge covered a wide range, integrated high-quality requirements. Most music teachers and mostly only skills, or bishop vocal or instrumental bishop, and integrated with a variety of teachers' knowledge quality is less, plus the heavy task of teaching and research, it is difficult to extract a large amount of time to carry out systematic and formal learning. In order to master multimedia music teacher as soon as possible this technology, as soon as possible to apply it to music teaching them to school should take some knowledge covered more widely, the overall quality of all aspects of higher teachers' professional and technical training to enable them to preliminary master within a relatively short period of time this technology, then carry out small-scale research or teaching, and in practice continues to deepen the depth and breadth of learning, thus becoming experts in this regard.

\section{Summary}

The rapid development and the gradual application of modern multimedia technology in the field of music education, in bringing us a new educational philosophy and educational model, but also for the majority of music educators will put forward higher requirements. As a music teacher in the 21st century, we must clearly aware of the technological revolution for classroom teaching as well as the impact brought about by our own, prompting us through a wide range of learning and continuously improve their literacy and knowledge to meet the needs of a new era , it is possible to complete the outstanding educational and teaching tasks. Of course, music teaching and research of multimedia technology environment is a complicated systematic project, not only need to practice and concluded in the short term, but long-term learning and exploration; not only teachers and students involved in school and learning, but also the whole society requires extensive attention and support. In this paper, the modern multimedia technology in music teaching put forward their plans and ideas, the aim of the initiate, but also looking forward to more music educators dedicated to research and practice in this area, so we can get more music education for the vast and far-reaching development in order to make our early music education modernization.

\section{References}

[1] Fang Zhining computer composer and arranger Beijing: Beijing Sports University Press, 2014.

[2] Reform and Suggestion Beijing Yin Aiqing Musical Pedagogy: the Chinese music education. 2011.

[3] The Ministry of Education Full-time compulsory education music curriculum standards People's

[4] Republic of China Beijing: Beijing Normal University Press, 2012.

[5] ARMY. New Curriculum and Subject Quality Training Beijing: China Textile Press, 2014. 